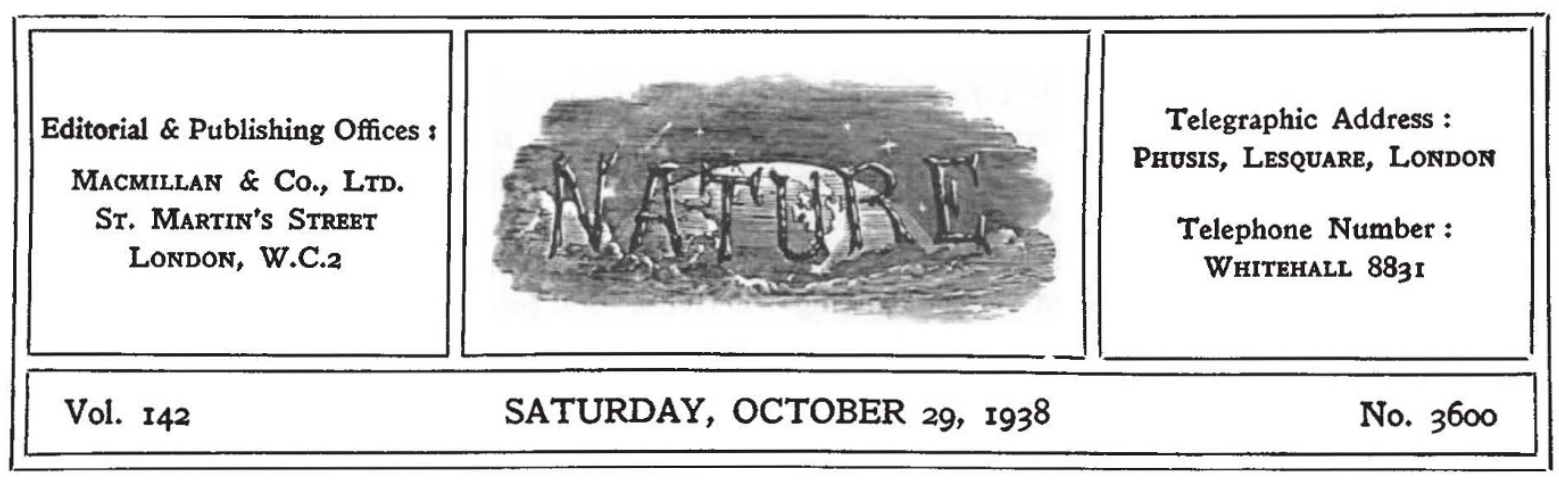

\title{
Social Science Problems and Programme
}

$\mathrm{W}^{\mathrm{n}}$ HEN the Council of the British Association meets next month, it will have before it the approval by the General Committee at the Cambridge meeting of the recommendation to create a new Division to deal with the social and international relations of science. So far, during the century or more of its existence, the work of the Association under the administration of the Council and subject to the approval of policy by the General Committee, has been carried on through the Sections, each dealing with a particular branch of science and meeting only once a year. As is implied by the deliberate choice of the term Division, the new organization is intended to operate on somewhat different lines, being intimately affiliated with the Association but semiautonomous. Much preliminary work will be required before the precise form and activities of the Division can be determined; but the main object of the Division, to further the objective study of the social relations of science, offers ample scope for undertaking research, including factual studies on the organization of science and its social and economic relations, for discussion of the social aspect of science, the consideration of the public relations of science, and for consultative work or as a co-ordinating centre and information bureau.

The science of society is still embryonic, and though the British Association may well prove to have taken a decisive step in accelerating its development, even the main lines of organization or activity of the new Division will probably require some time to determine. Apart from anything else, the relative merits of various lines of work, such as the actual initiation of research on particular subjects, and the various possibilities in regard to consultative or co-ordinating work, as well as to the importance of implementing means for bringing the findings of science more effectively before the general public, must be determined before the new Division can well allocate its resources and activities. Nor can it be indifferent to such recent developments as the founding of Nuffield College, Oxford, and the recently established National Institute for Economic and Social Research, London.

The extent and character of the investigations provided by such bodies will obviously be a matter of prime concern to the new Division in considering the initiation of any research project of its own. In considering the initial activities of the Division, however, especially in regard to factual research, the plan adopted by the Committee on Science and its Social Relations (C.S.S.R.) of the International Council of Scientific Unions should be of some assistance. This Committee is endeavouring to collect material for the preparation of a report and of bibliographies on the social relations of science, to be presented at the next meeting of the International Council of Scientific Unions in 1940. The report is designed to cover outstanding developments in the various branches of science, new applications of science in human society, the organization of scientific investigation and its application, with summaries of interpretative work on the world picture as given by science and its social relations.

In pursuance of this plan, the Committee has approached national academies and a number of international scientific organizations for assistance by the supply of relevant information. A number of correspondents have in this way been appointed to whom have been forwarded a questionnaire 
covering points in science in general and in special branches of science upon which information is required. These questionnaires should be of value in framing the initial policy of the new Division of the British Association. Obviously, as is implied in what has already been written, the Division should first have regard to the existing position of social research in Great Britain. It must have before it accurate information as to the extent and resources of the research effort in this field. Something of the nature of what may be termed a map of social research is called for at an early stage. To meet this requirement the Division might well decide to attempt to develop co-ordinating functions and activities and to establish a co-ordinating committee or information bureau, and also to establish relations with institutions dealing with social relations of science at home and abroad.

The required picture of research, however, cannot be limited to social research alone. Its significance can only be assessed when it is seen in its proper perspective in the general map of research effort, both scientific and industrial. For this reason, the Division might well consider implementing an inquiry into the nature, extent and resources available for scientific and technical research in Great Britain generally, on larger and more authoritative lines than the inquiry initiated some years ago by the Association of Scientific Workers.

Acquisition of precise data in this manner is undoubtedly an essential preliminary if the new Division is to utilize to the best advantage such resources as may be at its disposal for factual research in social sciences. Moreover, it can scarcely be doubted that apart from the researches actually initiated by the Division, its influence could most valuably be exerted to assist in such a reorientation or diversion of research effort from the physical to the biological sciences as has been urged by Prof. W. McDougall, Dr. Julian Huxley and others. Such representations would gain immensely in authority if supported by data drawn from such a survey as we have indicated.

The activities we have just suggested are of themselves likely to require the institution of effort or the establishment of organization to deal with many other matters contemplated in the memoranda submitted to the General Committee of the Association at Cambridge, such as the

blishment of consultative machinery, the of material for the information of the public, and so on. Moreover, the appointment of research committees similar to those constituted by the various sections of the Association must be one of the functions of the Division.

The initiation of research by the new Division requires, however, not only a survey of existing activities and resources but also the elaboration of an adequate plan of research. It is not essential to assume that the Division should alone be responsible for the actual initiation of research. One of its valuable functions, if it develops into the co-ordinating institution that is desired, may well be that of providing an authoritative plan of research desirable in the social field, the execution of which in detail is carried out by consultation with the various research institutions as well as by research committees of the Division.

What may be termed the research programme of the new Division might thus consist of a broad and long-range plan conceived in relation to the needs and opportunities as revealed by the information available, which would form the basis of detailed programmes, some of which might be executed by the Division itself and others by other institutions or some of the pro. fessional associations whose contribution at present is insignificant. Possession of a broad and longrange plan would, moreover, enable the Division to take the detached view essential if its recommendations from time to time regarding the diversion and re-orientation of research effort are to carry due weight and authority.

An admirable exposition of possibilities for basic research in this field has been given by Prof. H. Levy in a chapter on the scientific study of social development in his recent book: "A Philosophy for a Modern Man". Indeed, many of the features of social life which he enumerates as requiring quantitative measures constitute a programme which might with advantage be considered by the Division. These variables fall into three main groups. There are first the qualities which determine the technological level of the community, within which group are included all types of business and industrial enterprise. Then there are the qualities defining the physiological level of the population. In this group are included all those factors that determine the conditions under which people live. The third group comprises the qualities which define the cultural level of the population and includes all those mental and rsthetic qualities that thrive or are frustrated by the conditions imposed in the other two fields. 
Prof. Levy's approach is, indeed, very similar to that adopted by Lord Stamp in the programme of research outlined in his "Science and Social Adjustment" which also claims the attention of the new Division. Prof. Levy, indeed, reiterates in somewhat different form a number of Lord Stamp's proposals. He suggests, for example, the construction of an index of the degree of research activity in the community, and sub-indexes showing how this is composed of research in fields ranging from highly industrial and engineering to highly abstract, mathematical or logical. $\mathrm{He}$ suggests further a special index to measure the degree to which research is directed towards destructive ends rather than constructive progress.

Again, indexes are required to measure the general technical level of commodity production or the social waste in the distributive and pro. ductive processes, particularly in relation to the effect of intensive advertisement. Similarly, it should be possible to establish some standard of maximum social efficiency in shelter and housing provided for the community at any given time. This would imply a relative index of efficiency of housing and accommodation for various social classes. Like Lord Stamp, Prof. Levy directs attention to the need for a fundamental study of invention clearing in relation to patents and some index which would take account of factors hindering the assimilation or development of inventions. Technological unemployment is another topic presenting problems demanding quantitative study, while on the physiological side Prof. Levy urges the elaboration of an index of physical fitness applicable not only to individuals but also to social classes, as well as an environmental index, a food-value level based on the biological value of the food consumed by the individual, to be taken in association with the cost of living index figure, as well as a resistance index to measure the extent to which the individual can withstand the onset of various illnesses, diseases or epidemics.

Here alone indeed there is outlined a programme which the new Division might at first well find overwhelming. If, however, its organization and activities are conceived on broad, fundamental and long-range lines, there need be no fear of its being so immersed in the detail of a few investigations that it fails to exercise the co-ordinating and stimulating effect over the whole field that is desired. So far as specific researches may be concerned, its contribution, apart from the formulation of a broad plan, may well be in just those borderline problems, at the growing points of research in different departments of science which involve organized and many-sided efforts for their solution. While, therefore, the new Division may appoint research committees to report upon these and other matters, it will be desirable at an early stage to examine the data which must form the basis alike for a comprehensive plan of social research or for any representation designed either to re-orientate research effort or to stimulate fresh effort in professional or other quarters.

\section{A History of Bacteriology and Bacteriologists}

The History of Bacteriology

By Prof. William Bulloch. (University of London, Heath Clark Lectures, 1936, delivered at the London School of Hygiene and Tropical Medicine.) Pp. xii $+422+16$ plates. (London, New York and Toronto : Oxford University Press, 1938.) 10s. $6 d$. net.

SINCE the appearance of Löffler's fragmentary $S$ and otherwise faulty "Lectures" in 1887, students of the history of bacteriology have had no guide-book to this intriguing and complicated subject. They will all, therefore, welcome the present volume-written by the foremost living authority, who has lived through the heroic age and was personally acquainted with many of the heroes. It is true he had given us a foretaste of his knowledge in the "System of Bacteriology" (vol. 1, 1930) published by the Medical Research Council: but this larva is now metamorphosed into an imago which will surely serve the most exacting needs of historical students for at least another generation. Though originally deliveredlike Löffler's essay-in the form of lectures, this final product is actually a well-documented contribution to science.

The book is divided into eleven chapters dealing respectively with ancient doctrines of contagion; 